with the NHS and the freedom to step off the treadmill of piece rate NHS dentistry to devote time to private work. Furthermore, although dentistry has become a far more expensive component of health care, public protest has been surprisingly muted; demand for treatment of minor irregularities of teeth is influenced solely by ability and willingness to pay. ${ }^{10}$

Most important are the lessons for other sectors of the NHS. Direct charges for health care must be accompanied by rigorous and frequent appraisals of the public health, particularly in areas where the population might fall between the traditional providers and the as yet underfunded community services. Plans for further expansion of mixed public and private financing should also remove duplicative services; introduce integrated, cost effective monitoring; and allow implementation of policy. However, commercial motivation is powerful and persuasive and does not necessarily work in the interests of patients. In any event, health services research is crucially important to evaluate the results of this privatisation experiment, not least to inform the debate about future health care funding.

Perhaps the most surprising aspect of these developments has been the failure to recognise dental services as a model for mixed funding. In two years, more than a million people are likely to be contributing to private dental capitation schemes in Britain, and already expenditure on one dental surgical procedure, third molar removal, is as great in the private sector as it is in the NHS. ${ }^{11}$ In this context, the mixed franchise proposal is common sense. Yet the white paper Improving NHS Dentistry makes almost no mention of private care or how it can be integrated with NHS care. ${ }^{3}$ There is still no forum where purchasers and providers can discuss this interface or plan how best to target funding or improve clinical and cost effectiveness. If mixed public and private funding of dentistry is occurring by default, there is little hope for rational planning in the rest of health care.

JONATHAN P SHEPHERD Professor of oral and maxillofacial surgery DAVID W THOMAS Lecturer in oral and maxillofacial surgery PAUL SHEPHERD General dental practitione

Department of Oral Surgery, Medicine, and Pathology,

University of Wales College of Medicine,

Cardiff CF4 4XY

1 Healthcare 2000. UK health and health care services: challenges and policy options. London Healthcare 2000, 1995.

2 Kaletsky A. The National Health Service can survive as it is. Times 1995 Sept 21.

3 Department of Health. Improving NHS dentistry. London: HMSO, 1994.

4 Crawford AN. Recalled dental attendance: its cost to the NHS. Br Dent $f 1$ 1994;177.363-4.

5 Hutchinson I. Improving the poor prognosis of oral squamous cell carcinoma. BMf 1994;308:669-70.

6 Thomas DW, Satterthwaite J, Absi EG, Shepherd JP. Trends in the referral and treatment of new patients at an emergency dental clinic since 1989. Br Dent $\mathcal{f}$ (in press).

7 General Medical Services Committee. Patients presenting with dental problems: GP responsibility. London: BMA, 1993.

8 Pitts NB, Nugent $Z$. Capitation registration of Scottish 5 year olds related to caries prevalence and deprivation scores. $\mathcal{F}$ Dent Res 1995;74:857.

O'Brien M. Children's dental health in the United Kingdom 1993. London: HMSO, 1994

10 Shaw WC, O'Brien KD, Richmond S. Quality control in orthodontics: factors influencing the receipt of orthodontic treatment. Br Dent f 1991;170:66-8.

11 Shepherd JP, Brickley MR. Surgical removal of third molars. BMf 1995;309:620-1.

\section{Hospital at home}

\author{
An uncertain future
}

Providing services traditionally associated with secondary care in the community is a feature of health policy both in Britain and abroad. "Hospital at home" is currently a popular response to the increasing demand for hospital beds. Cutting costs by avoiding admission and reducing length of stay in hospital is a central goal of such schemes. Changes in medical technology, improvements in housing, and an increasing emphasis on primary care have all encouraged the idea that some hospital services can be provided safely and more cheaply in the community.

A national survey of purchasing authorities in Britain shows that most authorities are either supporting, or planning to support, a hospital at home scheme (S Iliffe and A Haines, unpublished data). All 136 health authorities, commissions, and health boards were asked to report planned or operational hospital at home schemes in their district. Hospital at home was defined as the provision of a service that prevented hospital admission, or facilitated early discharge from hospital. The purchasing authorities were also asked whether they provided specialist paediatric or mental health services or supported schemes that made use of intensive technologies such as renal dialysis or home parenteral nutrition. Seventy six per cent of those surveyed replied, and they reported 139 existing and 100 planned hospital at home schemes. Of these, paediatric and mental health services made up $21 \%$ and $12 \%$ of schemes in operation, and a further $15 \%$ and $21 \%$ of planned schemes. Only $15 \%$ of existing or planned schemes were providing or planning to provide specific technological services. A more detailed profile of hospital at home in Britain is currently being prepared by the Policy Studies Institute (N Fulop, personal communication).

Broadly speaking, hospital at home schemes are community or hospital based. Community based schemes build on existing resources, including district nurses and domiciliary provision of other services such as physiotherapy and occupational therapy. Clinical responsibility is usually assumed by general practitioners. In hospital based schemes, consultants provide clinical responsibility, and services are provided on an outreach basis with varying degrees of integration with community services.

Considerable heterogeneity exists within this framework. Some schemes are designed to care for specific conditions, such as the home ventilation service provided to patients requiring long term mechanical ventilation in south London. ${ }^{1}$ Other schemes provide specialist services, such as administration of intravenous antibiotics or parenteral nutrition. ${ }^{2}$ Much more common are schemes to care for patients discharged early from hospital after surgical, especially orthopaedic, procedures. ${ }^{3-6}$ Some schemes have an open door policy, admitting patients with an unrestricted range of conditions.?

This concentration on personal, nurse led care rather than provision of technical services is in contrast to the development of home care in other countries. In North America in particular, high technology home care, such as intravenous drug administration and blood transfusion, is well established. ${ }^{8}$ These schemes usually have close ties with acute hospitals and may be encouraged by the different structure of incentives in insurance based systems of health care.

It is, of course, essential that new types of service provision are formally evaluated before they are widely adopted. There is little published research on the relative costs and benefits of different forms of hospital at home in comparison to traditional hospital care. There are some randomised studies of the early discharge of patients after specific surgical procedures, including hernia repair, abdominal hysterectomy, and cholecystectomy. ${ }^{10}$ However, these were published 20 years 
ago and their relevance today is limited, given the overall reduction in length of hospital stay, the use of day case surgery, and the introduction of minimally invasive surgery. More recent studies have suggested that hospital at home is a safe and acceptable way of delivering care to patients after repair of a fractured femur ${ }^{3561112}$ or hysterectomy. ${ }^{1314}$ Another recent study, comparing patients with access to hospital at home to those with no access to the service, reported that hospital at home can be cheaper per bed day than hospital care for patients with a fractured femur. ${ }^{4}$ However, these studies were non-randomised and therefore prone to selection bias. One recent randomised study of elderly patients was limited by its small size. ${ }^{7}$ Three randomised trials of hospital at home are currently under way in Britain (UK Collaborative Group on Research and Development of Hospital at Home, North

1 Goldberg AI, Faure E. Home care for life supported persons in England. Chest 1984:86:910-4. 2 Mughal M, Irving M. Home parenteral nutrition in the United Kingdom and Ireland. Lancet 1986;Aug 16:383-7.

O'Caithain A. Evaluation of a hospital at home scheme for the early discharge of patients with fractured neck of femur. $f$ Public Health Med 1995;16:205-10.

4 Hollingsworth W, Todd C, Parker M, Roberts JA, Williams R. Cost analysis of early discharge after hip fracture. $B M \mathcal{F}$ 1993;307:903-6.

Pryor GA, Williams DR. Rehabilitation after hip fractures. Home and hospital management compared. I Bone foint Surg 1989;71B:471-4.

Goldthorpe P, Hodgson E, Evans E, Bradley JG. How we set up an audit of hospital at home in orthopaedic surgery. Medical Audit News 1994;4:40-3

7 Donald IP, Baldwin RN, Bannerjee M. Gloucester hospital at home: a randomized controlled trial. Age Ageing 1995;24:434-9.

8 Marks L Home and hospital care: redrawing the boundaries. London: King's Fund Institure, 1991
Thames Regional Health Authority), ${ }^{15}$ and the first results should be available in 1997 . Until the results of these, and other, studies are available, it will be unclear whether hospital at home schemes represent a new, cost effective direction for health service provision or are merely a substitute technology of limited value and lifespan.

SASHA SHEPPERD Research officer

Health Services Research Unit,

Department of Public Health and Primary Care,

University of Oxford,

Oxford OX2 6HE

STEVE ILIFFE

Reader in primary care

University College London Medical School,

London N19 5NF

Gerson LW, Collins JF A randomized controlled trial of home care: clinical outcome for five surgical procedures. Can $\mathcal{F}$ Surg 1976;19:519-23.

10 Adler MW, Waller JJ, Ca S A. Thorne SC Randomised controlled trial of early discharge for inguinal hernia and varicose veins. 9 Epidemiol Community Health 1978;32:136-42.

11 Farnworth MG, Keeney P, Shiell A. The costs and effects of early discharge in the managemen of fractured hip. Age Ageing 1994;23:190-4.

12 Sikorski JM, Senior J. The domiciliary rehabilitation and support program: rationale, organisation and outcome. Med $\mathcal{F}$ Aust 1993;159:23-5.

13 Hackman B, Navaneethan N. Early discharge after gynaecological surgery. Eur 7 Obstet Gynaecol Reprod Biol 1993;52:57-61.

14 Hancock KW, Scott JS. Early discharge following vaginal hysterectomy. Br $\mathcal{f}$ Obstet Gynaecol 1993;100:262-4.

15 Wisely J, Haines A. Commissioning a national programme of research and development on the interface between primary and secondary care. $B M \mathcal{F}$ 1995;311:1080-2.

\section{Health and human rights}

\section{Protecting human rights is essential for promoting health}

When the World Health Organisation redefined health as "a state of complete physical, mental and social well-being" it not only expanded health far beyond medicine, it openly acknowledged the vast accumulated knowledge about the central role of societal determinants of population health. Despite the public's belief to the contrary, medical care is a relatively minor, albeit important, contributor to health, ${ }^{2}$ far outweighed by societal factors, of which social class has been the most extensively studied. ${ }^{34}$

In 1988, a seminal report by the United States Institute of Medicine defined the mission of public health as "ensuring the conditions in which people can be healthy." In turn, this required those working in public health to consider the societal nature of these essential conditions in which people could achieve the highest attainable standard of physical, mental, and social wellbeing. Paradoxically, the discipline of public health has generally ignored the societal roots of health in favour of medical interventions, which operate further downstream. For example, public health efforts at preventing and controlling sexually transmitted diseases have focused on diagnosis and treatment, along with educational programmes, rather than confronting societal inequality or other societal issues as "essential conditions" underlying the spread of sexually transmitted diseases. Epidemiological research has contributed to this narrowed focus, ${ }^{5}$ because it identifies individual risk behaviours in isolation from the critical societal context.

Public health's difficulty in addressing the indisputably predominant societal determinants of health status is exacerbated by the lack of a coherent conceptual framework for analysing societal factors that are relevant to health; the social class approach, while useful, is clearly insufficient. ${ }^{2}{ }^{36}$ Public health action based on social class is often simply accusatory, and it raises, but cannot answer, the question: "what must be done?"
In this sense, "poverty" as a root cause of ill health is both evident and paralysing to further thought and action. Also, without a consistent approach or vocabulary, we cannot identify the societal factors common to different health problems (cancer, heart disease, injuries, infectious diseases) and to different countries. Finally, since the way in which a problem is defined determines what is done about it, the prevailing public health paradigm is unclear about the direction and nature of societal change that is needed to promote public health.

Modern human rights, born in the aftermath of the second world war and crystallised in the Universal Declaration of Human Rights of 1948, reflect a broader, societal approach to the complex problem of human wellbeing. The implicit question behind the modern human rights movement is: "what are the societal (and particularly governmental) roles and responsibilities to help promote individual and collective wellbeing?" This form.of the question leads to a specific list of actions that governments should not do (discriminate, torture, imprison under inhumane conditions, interfere with the free flow of information, invade privacy, prevent associative life in society), and a basic minimum that governments should ensure for all (elementary education, housing, food, medical care). While the word health is mentioned only once in the document, to a public health professional the declaration is about the societal preconditions for "physical, mental and social well-being."

The current health and human rights movement is based on a working hypothesis: that the human rights framework provides a more useful approach for analysing and responding to modern public health challenges than any framework thus far available within the biomedical tradition. The discussion is complicated by the fact that health professionals are generally unaware of the key concepts, meaning, and content of modern human rights. Yet awareness is increasing. Health professionals 